\title{
Nuchal-Type Fibroma
}

National Cancer Institute

\section{Source}

National Cancer Institute. Nuchal-Type Fibroma. NCI Thesaurus. Code C6486.

A rare non-encapsulated and poorly circumscribed lesion that usually affects the posterior neck. It is seen more frequently in men and is characterized by the presence of thick collagen fibers. It may recur but does not metastasize. 